\title{
ORIGINAL
}

\section{Ghrelin in small intestine, its contribution to regulation of food intake and body weight in cross-intestinal parabiotic rats}

\author{
Hitoshi Noguchi $^{1)}$, Takayuki Masaki ${ }^{2)}$, Tetsuya Kakuma ${ }^{2)}$, Masamitsu Nakazato ${ }^{3)}$ and Hironobu Yoshimatsu ${ }^{2)}$ \\ 1) Noguchi Thyroid Clinic and Hospital Foundation, Beppu 874-0932, Japan \\ 2) Oita University School of Medicine, Internal Medicine 1, Yufu 879-5593, Japan \\ 3) Miyazaki University School of Medicine, Internal Medicine 3, Miyazaki 889-1692, Japan
}

\begin{abstract}
Ghrelin has been shown to be associated with feeding behavior in humans and rodents. It has been suggested that ghrelin may play a role behind the effect of bariatric surgery. Inbred rats were made into parabiotic pairs so that they shared a single abdominal cavity. A further operation is performed later in which the small intestines are transected and reconnected so that one rat continually lost nutrition to its partner. Changes in food intake and body weight were recorded. Seven weeks later, content of ghrelin in the plasma, stomach and upper intestines were measured in the paired rats. Rats which lost nutrients to its counterpart (Loss rats) ingested significantly more food than sham control rats $(p<0.001)$. Rats which gained nutrient (Gain rats) ingested less than controls $(p<0.001)$. There was no significant difference in body weight, blood glucose, insulin, free fatty acids and triglycerides between the paired rats. There was significantly higher levels of ghrelin in the plasma $(p<0.008)$ and the intestine of the Loss rats $(p<0.02)$. There were no difference in ghrelin in the stomach between parabiotic rats and sham operated controls. The ghrelin content of the plasma and intestines were significantly higher in the Loss rats, which ate more, and normal in the Gain rats, which ate less than controls. Because no remarkable changes in the ghrelin content were observed in the stomach, difference in the quality of the chime may affect the local synthesis and release of ghrelin.
\end{abstract}

Key words: Ghrelin, Parabiosis, Feeding, Behavior

GHRELIN, an endogenous ligand for growth hormone secretagogue receptors (GHS-R), is a gastrointestinal hormone primarily isolated from the stomach [1]. Ghrelin which has been also identified in other tissues including the intestines, [2] has received much attention about its possible role in the pathogenesis of obesity $[7,8,9,10]$.

The various studies involving ghrelin to this day have provided evidence about its functional role in feeding regulation. Central as well as peripheral administration of ghrelin have been shown to increase food intake and body weight in rodents $[11,12,13,14]$. It has also been demonstrated that serum level of ghrelin is increased by fasting $[15,16]$ and decreased by refeeding [13]. These previous studies indicate that ghrelin plays an important role in the regulation of energy metabolism.

Received Mar. 11, 2011; Accepted Apr. 27, 2011 as K11E-085 Released online in J-STAGE as advance publication May 26, 2011

Correspondence to: Hitoshi Noguchi, Noguchi Thyroid Clinic and Hospital Foundation, 6-33 Noguchi-Nakamachi, Beppu, Oita 8740932, JapanE-mail: hnoguchi@noguchi-med.or.jp
However, in human studies, contradictory results have been reported. Obese human subjects showed lower level of serum ghrelin than lean human subjects [8]. Some have suggested that smaller fluctuation in the serum ghrelin concentration of obese subjects contribute to the excessive feeding [9]. In contrast, a serum level of ghrelin is known to decrease in human subjects who have undergone bariatric surgery. Patients with bariatric surgery display significant weight loss accompanied by lower serum ghrelin levels and its reduced fluctuation [15].

The secretion of ghrelin may be triggered by direct stimulation to the gastro-intestinal wall by nutrients in the lumen. Another possible mechanism is that it is triggered by neural or hormonal signals from elsewhere in the body after nutrition is absorbed by the intestines. In human and scheduled-fed animal, preprandial increase of serum ghrelin was observed without immediate mechanical stimuli in gastrointestinal tract $[17,18]$ indicating a mediation of the central nervous system in production and/or secretion of ghrelin. 
Whereas, the instant postprandial decrease [19] and the anatomical location of ghrelin producing cells [1, 5] suggest the involvement of mechanical stimuli or change in post-absorptive humoral factors in inhibitory regulation of ghrelin through the sensors along the gastrointestinal lumen.

In order to further elucidate the nature of this hormone, we employed Koopmans' cross-intestinal parabiotic rat model [22]. In this model, one rat continually gained or lost nutrient in the intestine from or to the other rat, respectively, through the transplanted intestine. Regardless of their increased or decreased ingestion of nutrient, the animals show little difference in body weight and major blood parameters such as glucose and insulin at four weeks post operation. However, animals eat dramatically more or less than their corresponding pairs. This model is used to study various aspects of feeding behavior, but the mechanisms by which its food intake is modulated is as yet unknown. We hypothesized that change in ghrelin of gastrointestinal tract might have a role in modulating their feeding behavior. To address this issue, we analyzed the relationship between food intake and changes in local and systemic ghrelin levels in parabiotic rats.

\section{Animals \\ Adult, male [12-14 weeks old, 250-300g) Lewis rats were kept in a clean, air conditioned environment at $22 \pm 1^{\circ} \mathrm{C}$ in 12 hour light-dark cycles throughout the experiment. The rats were normally kept in standard cages with bedding. Liquid food was given everyday at $4 \mathrm{pm}$ and removed at 11am (a span of 19 hours) to correspond with the natural feeding cycle of the rats. Water was provided in a separate bottle ad libitum. All work involving rats was done in accordance with the principles set forth in the NIH Guide for the Care and Use of Laboratory Animals and all animal protocols were approved by the Animal Care and Use Committee of the University of Oita School of Medicine.}

\section{Surgery}

Inbred Lewis rats matched for body weight to within $5 \mathrm{~g}$ of each other were paired and surgically made into parabiotic rats which shared a common abdominal cavity. The rats were allowed to recuperate for two weeks during which they were adapted to liquid diet (Ensure Liquid, Abbot) and feeding measurements were taken to ensure that there was no initial lateral difference. They were then given secondary operations in which a segment of the upper gut from one rat was transplanted into the other rat in a pedicle transposition so that the food ingested through the mouth of the recipient rat will first pass through the segment transplanted from the donor rat before it is reintroduced into the corresponding gut of the recipient rat. The mesentarium is left intact on the transplanted segment along with the local nerves and blood vessels (Fig. 1). Thus the food absorbed from this segment will nourish the individual of its origin. The recipient rat, which lost luminal nutrition to the paired rat, was denoted the Loss rat, while the donor rat, which gained luminal nutrition beyond what it ingested orally, was named the Gain rat. The details of the surgical procedure are described elsewhere [22]. Sham operated controls were likewise paired and their guts were similarly sectioned but re-sutured into the original position. In cases where samples from sham operated controls were damaged or lost, we used non-operated rats given the same liquid diet for a corresponding number of weeks.

\section{Feeding Measurements}

Food intake was measured in restraining cages which allowed each animal to drink liquid diet only from the bottle allotted to it. They were placed in restraining cages for the same duration of time as their normal feeding hours. A minimum of three days' interval was inserted between measurements so as to avoid the effect of restraint on the feeding. At least three measurements were taken on each pair and an average was used as the representative value for each pair.

\section{Sacrifice and Assays}

Six pairs were sacrificed for ghrelin assay. The animals were sacrificed, separated, weighed for individual body weight, and $6-8 \mathrm{~mL}$ of blood was sampled from each animal. The blood was centrifuged with EDTA to collect plasma for ghrelin assay. The plasma was frozen at $-80{ }^{\circ} \mathrm{C}$ until RIA assay. The stomach and anatomically equivalent sections of the upper gut were also sampled. The tissues were placed in test tubes containing distilled water and boiled at $100{ }^{\circ} \mathrm{C}$ for $3 \mathrm{~min}-$ utes and immediately put on ice. Distilled water, $100 \%$ ascetic acid and $0.5 \mathrm{~N}$ hydrochloric acid were added so that ascetic acid will account for $6.25 \%$ of final volume and $\mathrm{HCl}$ will account for $2 \%$ of final volume. The tissues were then homogenized and kept at $4{ }^{\circ} \mathrm{C}$ until RIA assay. Protein content of the supernatant was quantified using BioRad Protein assay kit. RIA values were 

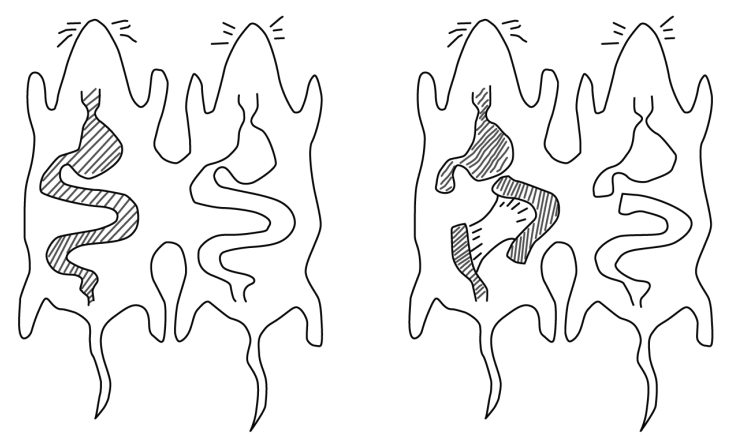

2

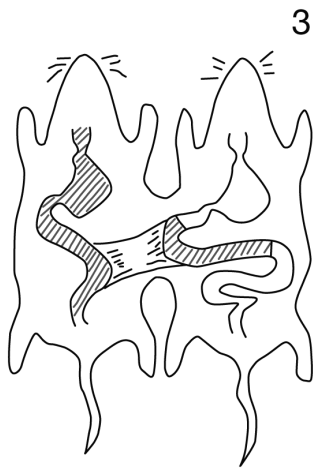

Fig. 1a 1. Two Lewis rats matched for body weight were sutured together so that they share a common abdominal cavity. 2. A section of the upper jejunum was transected but with the mesenterium left intact. The jejunum of the recipient was transected in the equivalent position. 3 . The upper and lower intestines of the donor were connected to create a shorter intestine while the transected gut segment was introduced into the digestive tract of the recipient to create a longer intestine.

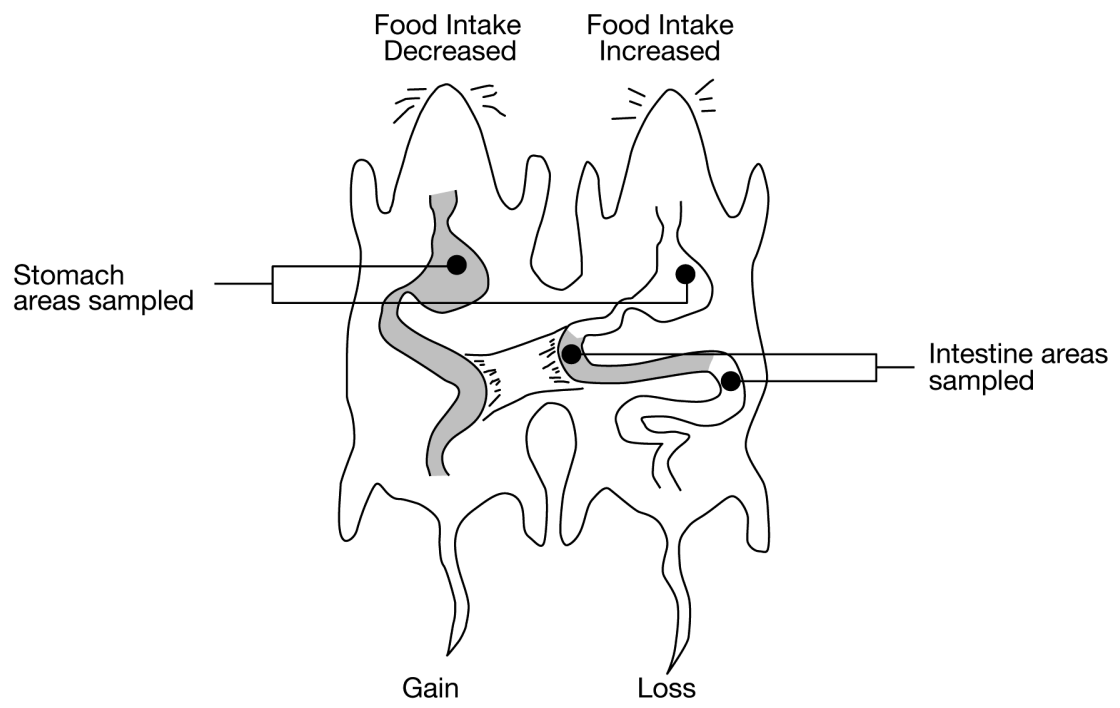

Fig. 1b A section of the intestine of the "gain" rat was surgically introduced into the intestinal tract of the "loss" rat in a pedicle transposition. The "loss" rat continuously lost nutrition into the bloodstream of the "gain" rat. The "gain" rat consequently ate less and the "loss" rat ate more. Anatomically equivalent areas of the stomach and the intestines were sampled upon sacrifice.

standardized to per milligram protein bases.

The RIA assay for ghrelin was performed at Department of Internal Medicine 3, Miyazaki Medical University using in-house ghrelin antibodies as described elsewhere [21].

Serum glucose, triglycerides, free fatty acids and insulin were assayed by SRL Inc.

\section{Statistics}

Mann-Whitney-U test was employed in the statistics. StatView 5.0 was used for the calculations.

\section{Results}

\section{Changes in body weight and food intake of parabi- otic rats}

Fig. 2 shows the body weight of the rats upon sacrifice. The body weights of Gain and Loss rats were $413.2 \mathrm{~g}$ ( $\pm 11.0 \mathrm{SE})$ and $410.1 \mathrm{~g}( \pm 19.9 \mathrm{SE})$ respectively. There were no significant differences in body weight between gain and loss rats at 4 weeks after secondary surgery and the deviation was comparable to that of the sham operated controls. However, there was a small but significant increase in the body weight of the Gain rats over the Loss 
rats after 6 weeks (data not shown). All samples were taken from rats 4 weeks after secondary surgery to avoid interference of body weight differences.

\section{Changes in food intake}

Fig. 3 shows the changes in food intake in parabiotic rats. There was no difference in the food intake within the parabiotic pairs before the intestinal surgery. There was a significant difference $(p<0.005)$ in food intake after the intestinal transplants. Food intake in Loss and Gain rats significantly increased or decreased, respectively, compared with that in sham-operated control rats $(p<0.001)$. It should be noted that the animals were given two weeks to recuperate from the fist surgery before pre-operative feeding measurements were taken and another four weeks after the second surgery before post-operative feeding measurements were taken. The post-operative rats were therefore 4 weeks older than the pre-operative rats on average. Thus the post-operative parabiotic rats and sham-operated controls ate slightly more than the pre-operative animals. For this reason, the post-operative food intake of the Gain rats is not significantly lower than the pre-operative baseline, but is significantly lower than that of the post-operative controls which were of the same age (Koopmans used older rats in excess of $350 \mathrm{~g}$, which were not in steady supply at our locale, and was free from the changes in food intake due to growth of the animals).

\section{Changes in ghrelin content in gastrointestinal tract of parabiotic rats}

The RIA measurements of ghrelin in the upper gut showed significantly higher level in the Loss rats ( $586.4 \mathrm{fmol} / \mathrm{mg}$ protein $\pm 14.6 \mathrm{SE}$ ) than the Gain rats ( $469.7 \mathrm{fmol} / \mathrm{mg}$ protein $\pm 14.6 \mathrm{SE})(p<0.008)$ as well as sham control rats $(411.2 \mathrm{fmol} / \mathrm{mg}$ protein $\pm 42.0 \mathrm{SE}$ ) $(p<0.02)$ (Fig. 5). There were no significant difference in ghrelin level between Gain rats and sham controls. We also measured the ghrelin in the lower gut but there was no significant difference (data not shown). There were no significant differences in ghrelin concentration in the stomach between gain and loss rats and also between each parabiotic rats and controls (Fig. 6)

\section{Changes in conventional parameters}

As with previous reports using the same model, there were no differences in serum glucose, insulin, triglycerides and free fatty acids between the paired rats.

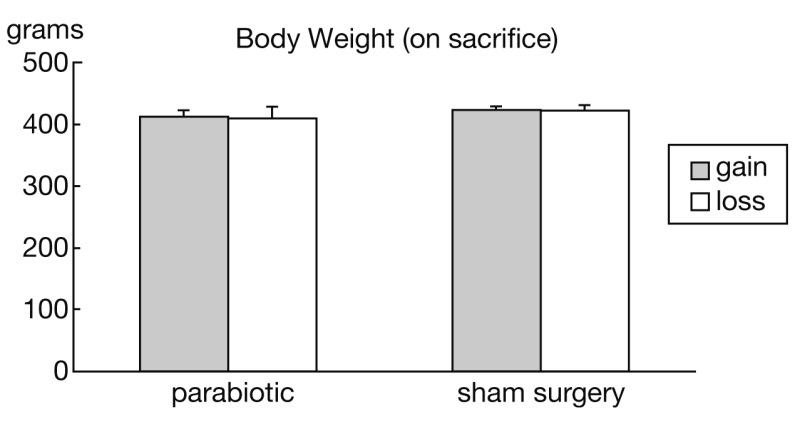

Fig. 2 In grams of body weight at sacrifice. There was no significant difference in the body weight of the matched pairs at sacrifice when separated along the suture lines.

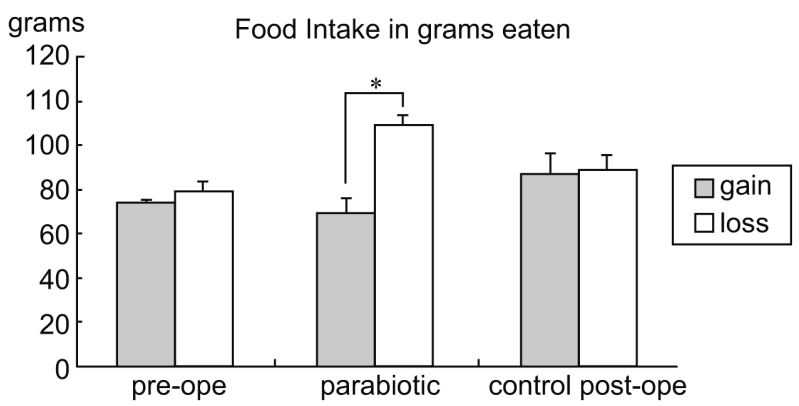

Fig. 3 In grams of liquid diet eaten. Approx. 1Kcal/gram. There was no significant difference before the intestines were re-routed. The Gain side ate significantly less and the Loss side significantly more after the surgery. The postoperative rats were 4 weeks older than the pre-operative rats on average and were consequently larger and ate more. For this reason, the post-operative food intake of the Gain rats is not significantly lower than the pre-operative baseline, but is significantly lower than that of the postoperative controls which were of the same age (Koopmans used older rats in excess of $350 \mathrm{~g}$, which were not in steady supply at our locale, and was free of this discrepancy).

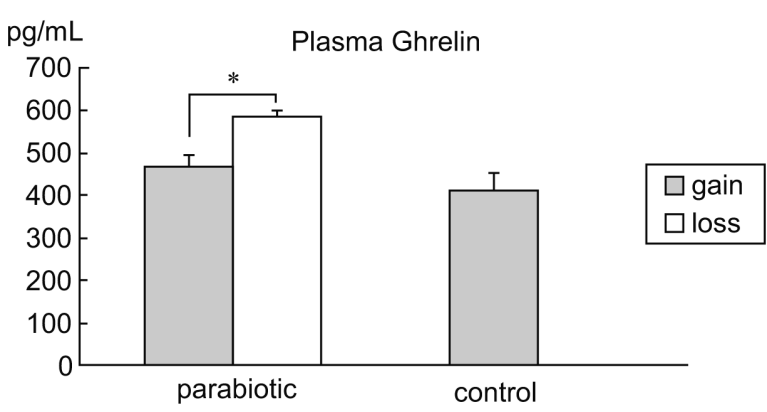

Fig. 4 Plasma ghrelin levels were significantly increased in the loss side in the parabiotic group. An average of 12 similarly fed, but non-operated, rats is presented as control. 


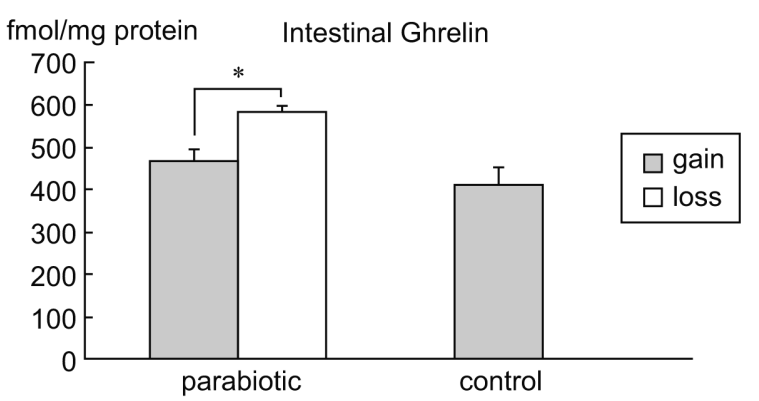

Fig. 5 The ghrelin content of the intestinal tissue (in fmol/mg protein) was significantly higher in the Loss group. An average of 12 similarly fed, but non-operated, rats is presented as control.

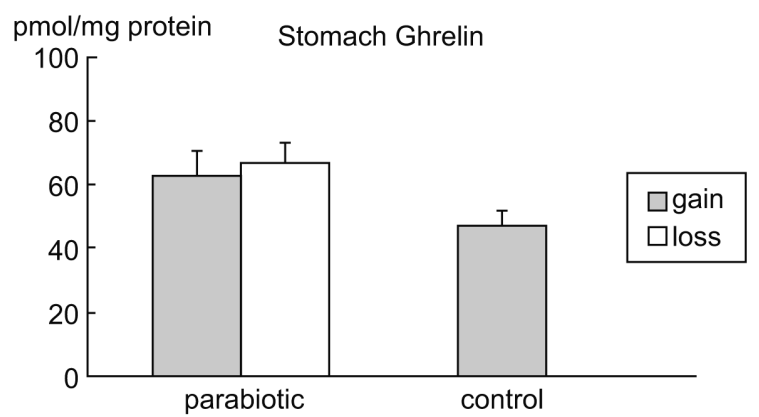

Fig. 6 There was no significant difference in the ghrelin content in the stomach tissue (in $\mathrm{pmol} / \mathrm{mg}$ protein). An average of 12 similarly fed, but non-operated, rats is presented as control.

\section{Discussion}

These experiments were conducted circa 19992003. The original objective was to show that ghrelin had a role in modulating the feeding behavior of crossintestine parabiotic rats and thereby suggest that bariatric surgery in humans may also function by a similar mechanism. Cummings et al reported, in 2002, ghrelin data from human gastric bypass patients that was partly what this animal experiment was meant to predict [15].

In cross intestinal parabiotic rats, the Loss rats lose nutrition into the bloodstream of the Gain rats through a segment of intestine transplanted in a pedicle transposition (Fig. 1). Since Gain rats absorb nutrition from the Loss rats on top of the nutrition that it ingests by itself, a great difference in energy intake between Gain and Loss rats is expected. However, a dramatic change in food intake adjusts for the difference in absorption with little or no resultant difference in body weight or serum borne metabolites at four weeks after the cross-intestinal surgery. It has not been explained how parabiotic rats recognize the changes in their nutrient absorption and reflect it on their feeding behavior. It is unlikely that changes in humoral factors such as glucose and insulin affect food intake since they show no remarkable difference.

Ghrelin has been shown to be involved in the regulation of feeding behavior. So we focused on ghrelin as an intestine-derived signal to regulate food intake in parabiotic rats. Results showed that the plasma ghrelin was significantly higher in the Loss rats than in the Gain rats as well as sham control rats (Fig. 4). However, ghrelin level in Gain rats showed no remarkable change from controls. The Loss rats that ate more showed higher levels of plasma ghrelin, while the gain rats that ate less showed normal levels. Ghrelin being an orexigenic substance [20, 28, 29, 30], the correlation between ghrelin level and food intake suggests that ghrelin may be involved in the regulation of feeding behavior in response to intestinal transplantation.

Thus, it is probable that parabiotic treatment has induced change in plasma ghrelin levels through affecting its production and/or release from gastrointestinal tract. We found no difference in the ghrelin content in stomachs between gain and loss rats, even though the stomachs were exposed to different amounts of food. This result suggests that food volume per se may not affect ghrelin levels in the stomach. It is known that serum ghrelin is increased preprandially and decreased postprandially [19, 28, 29] indicating suppressive effect of food on the production of ghrelin. In the postprandial phase, direct contact of nutrition against the wall of the digestive tract or changes in post-absorptive humoral factors could trigger the suppression of ghrelin. If humoral factors regulate ghrelin, then we should see the same changes in grelin content in the stomach as well. But we found no difference in the stomach ghrelin, while there was significant difference in the intestinal ghrelin. Thus, it seems more likely that the change in ghrelin is controlled locally by the intestinal tract itself.

Small intestines sampled in the present study for measurement of ghrelin are anatomically equivalent areas while each segment of the intestine changed their relative positions upstream or downstream of intestinal tract. The segment downstream is exposed to chime that has been further digested and more depleted nutrition than the segment upstream. Anatomically equiv- 
alent segments of the intestine exposed to lower concentrations of nutrition showed higher content of ghrelin than segments exposed to higher concentration of nutrition.

Small intestine in Gain rats maintains its upstream position in the intestinal tract even after transplantation. It is therefore reasonable that no remarkable change in ghrelin levels was observed in the transplanted segment of the intestines of Gain rats. But food intake of Gain rats were decreased compared to controls. It can be speculated that ghrelin is not the only factor controlling food intake and other factors such as chlecystokinin (CCK) and GLP-1 may inhibit food intake of Gain rats in response to local food stimulation.

How the ghrelin signal reaches the brain is still open to debate. Present study demonstrated that blood ghrelin level in Loss rats increased from $480.5 \mathrm{pg} / \mathrm{mL}$ to $558.4 \mathrm{pg} / \mathrm{mL}$, an increase of mere $16 \%$, a relatively small change compared to other studies. It is unlikely that this increased blood ghrelin may affect food intake because this alternation is too small compared with physiological periplandial change in blood ghrelin level of rats $[12,13]$. Rather, it is possible that the afferent neuronal pathway is involved in its signal transmission to the brain. It has been shown that stomach ghrelin relays its signal to the brain via gastric vagal afferent nerves [23]. Signal transmission from small intestine mediated by vagal afferent nerve has been also identified in intestinal peptides such as CCK [24] and GLP-1[25]. So it can be hypothesized that small change in local intestinal ghrelin level may affect food intake by signal transmission via vagal afferent nerve. Other studies dispute the contribution of the vagal afferent nerve for ghrelin's effect on food intake. It has been shown that completely vagotomized rats can respond to intraperitoneal injections of very large doses of ghrelin (up to $40 \mathrm{microgram} / \mathrm{Kg}$ ) [26]. This study found substantial changes in food intake with much smaller changes in systemic ghrelin for which the vagal afferent nerve may be a vital component. The surgical manipulation could not have had any more influence to the vagal nerves of the Loss and Gain rats than to the sham-operated controls since the surgery itself was identical except for the way the intestines were re-connected. (Although this report shows ghrelin data from non-operated controls, the feeding and body weight data are from sham operated controls). Surgical manipulation can affect ghrelin in other ways. Another study which employed Bilroth II and Roux-en-Y reconstruction on gastorectomized rats have shown that in the absence of stomach-derived ghrelin, intestine-derived ghrelin can increase and fill in for the loss [27]. In this study, however, stomach-derived ghrelin was not different from that of sham operated controls. The Gain rats in a parabiotic pair do gain weight when compared to Loss rats after six weeks, but since these rats were sacrificed at four weeks before significant body weight differences appear, weight related factors such as leptin probably did not influence the outcome.

The above study may provide several insights about the role of gastrointestinal tract in regulation of feeding behavior as follows. Parabiotic rats may compensate their altered energy intake induced by intestinal transplantation through the modulation of their food intake. Change in ghrelin levels of the small intestine may be involved in the regulation of feeding behavior in response to intestinal transplantation. Intestinal tract may sense the nutritional content of the chime to regulate synthesis and/or release of ghrelin. Further study is necessary to clarify the local mechanism to affect intestinal ghrelin and its signaling pathway to the brain.

\section{Disclosure}

The authors have no conflicts of interests.

\section{Ethics}

All work involving rats was done in accordance with the principles set forth in the NIH Guide for the Care and Use of Laboratory Animals and all animal protocols were approved by the Animal Care and Use Committee of the University of Oita School of Medicine.

\section{Dedication}

This work is dedicated to the memory of Henry S. Koopmans, PhD. (1944-2010), former professor at the University of Calgary who developed the cross-intestinal parabiotic rat model. 


\section{References}

1. Kojima M, Hosoda H, Date Y, Nakazato M, Matsuo H, Kangawa K (1999) Ghrelin is a growth-hormonereleasing acylated peptide from stomach. Nature 402(6762):656-660.

2. Mori K, Yoshimoto A, Takaya K, Hosoda K, Ariyasu H, Yahata K, Mukoyama M, Sugawara A, Hosoda H, Kojima M, Kangawa K, Nakao K (2000) Kidney produces a novel acylated peptide, ghrelin. FEBS Lett 486(3):213-216.

3. Gualillo O, Caminos J, Blanco M, Garcia-Caballero T, Kojima M, Kangawa K, Dieguez C, Casanueva F (2001) Ghrelin, a novel placental-derived hormone. Endocrinology 142(2):788-794.

4. Korbonits M, Kojima M, Kangawa K, Grossman AB (2001) Presence of ghrelin in normal and adenomatous human pituitary. Endocrine 14(1):101-104.

5. Kanamoto N, Akamizu T, Hosoda H, Hataya Y, Ariyasu H, Takaya K, Hosoda K, Saijo M, Moriyama K, Shimatsu A, Kojima M, Kangawa K, Nakao K (2001) Stomach is a major source of circulating ghrelin, and feeding state determines plasma ghrelin-like immunoreactivity levels in humans. J Clin Endocrinol Metab 86(10):4753-4758.

6. Kanamoto N, Akamizu T, Hosoda H, Hataya Y, Ariyasu H, Takaya K, Hosoda K, Saijo M, Moriyama K, Shimatsu A, Kojima M, Kangawa K, Nakao K (2001) Substantial production of ghrelin by a human medullary thyroid carcinoma cell line. J Clin Endocrinol Metab 86(10):4984-4990.

7. Tschop M, Weyer C, Tataranni PA, Devanarayan V, Ravussin E, Heiman ML (2001) Circulating ghrelin levels are decreased in human obesity. Diabetes 50(4):707709.

8. Shiiya T, Nakazato M, Mizuta M, Date Y, Mondal MS, Tanaka M, Nozoe S, Hosoda H, Kangawa K, Matsukura S (2002) Plasma ghrelin levels in lean and obese humans and the effect of glucose on ghrelin secretion. $J$ Clin Endocrinol Metab 87(1):240-204.

9. Hansen TK, Dall R, Hosoda H, Kojima M, Kangawa K, Christiansen JS, Jorgensen JO (2002) Weight loss increases circulating levels of ghrelin in human obesity. Clin Endocrinol (Oxf) 56(2):203-206.

10. Muccioli G, Tschop M, Papotti M, Deghenghi R, Heiman M, Ghigo E (2002) Neuroendocrine and peripheral activities of ghrelin: implications in metabolism and obesity. Eur J Pharmacol 440(2-3): 235-254.

11. Lawrence CB, Snape AC, Baudoin FM, Luckman SM (2002) Acute central ghrelin and GH secretagogues induce feeding and activate brain appetite centers. Endocrinology 143(1):155-162.

12 Wren AM, Small CJ, Abbott CR, Dhillo WS, Seal LJ, Cohen MA, Batterham RL, Taheri S, Stanley SA, Ghatei MA, Bloom SR (2001) Ghrelin causes hyperphagia and obesity in rats. Diabetes 50(11):2540-2547.

13. Tschop M, Smiley DL, Heiman ML (2000) Ghrelin induces adiposity in rodents. Nature 407(6806):908913.

14. Wren AM, Small CJ, Ward HL, Murphy KG, Dakin CL, Taheri S, Kennedy AR, Roberts GH, Morgan DG, Ghatei MA, Bloom SR (2000) The novel hypothalamic peptide ghrelin stimulates food intake and GH secretion. Endocrinology 141; 4325-4328.

15. Cummings DE, Weigle DS, Frayo RS, Breen PA, Ma MK, Dellinger EP, Purnell JQ (2002) Plasma ghrelin levels after diet-induced weight loss or gastric bypass surgery. N Engl J Med 346(21):1623-1630.

16. Toshinai K, Mondal MS, Nakazato M, Date $\mathrm{Y}$, Murakami N, Kojima M, Kangawa K, Matsukura S (2001) Upregulation of Ghrelin expression in the stomach upon fasting, insulin-induced hypoglycemia, and leptin administration. Biochem Biophys Res Commun 281(5):1220-1225.

17. Cummings DE, Purnell JQ, Frayo RS, Schimidova $\mathrm{K}$, Wisse BE, Weigle DS (2001) A preprandial rise in plasma ghrelin levels suggests a role in meal initiation in humans. Diabetes 50; 1714-1719.

18. Sugino T, Hasegawa Y, Kikkawa Y, Yamaura J, Yamagishi M, Kurose Y, Kojima M, Kangawa K, Terashima Y (2002) A transient ghrelin surge occurs just before feeding in scheduled meal-fed sheep. Biochemical and Biophysical Research Communication 295, 255-260.

19. Shiiya T, Nakazato M, Mizuta M, Date Y, Mondal MS, Tanaka M, Nozoe S, Hosoda H, Kangawa K, Matsukura S. (2002) Plasma ghrelin levels in lean and obese humans and the effect of glucose on ghrelin secretion. $J$ Clin Endocrinol Metab 87(1):240-244.

20. Asakawa A, Inui A, Kaga T, Yuzuriha H, Nagata T, Ueno N, Makino S, Fujimiya M, Niijima A, Fujino MA, Kasuga M (2001) Ghrelin is an appetite-stimulatory signal from stomach with structural resemblance to motilin. Gastroenterology 120(2):337-345.

21. Date Y, Kojima M, Hosoda H, Sawaguchi A, Mondal MS, Suganuma T, Matsukura S, Kangawa K, Nakazato M (2000) Ghrelin, a novel growth hormone-releasing acylated peptide, is synthesized in a distinct endocrine cell type in the gastrointestinal tracts of rats and humans. Endocrinology 141(11):4255-4261.

22. Koopmans HS, McDonald TJ, DiGirolamo M (1997) Morphological and metabolic changes associated with large differences in daily food intake in crossed-intestines rats. Physiol Behav 62(1):129-136.

23. Date Y, Murakami N, Toshinai K, Matsukura S, Niijima A, Matsuo H, Kangawa K, Nakazato M (2002) The role of the gastric afferent vagal nerve in ghrelin-induced feeding and growth hormone secretion in rats. 
Gastroenterology 123(4):1120-8.

24. Smith GP, Jerome C, Cushin BJ, Eterno R, Simansky KJ (1981) Abdominal vagotomy blocks the satiety effect of cholecystokinin in the rat. Science 213(4511):10361037.

25. Bucinskaite V, Tolessa T, Pedersen J, Rydqvist B, Zerihun L, Holst JJ, Hellström PM (2009) Receptormediated activation of gastric vagal afferents by glucagon-like peptide-1 in the rat. Neurogastroenterol Motil. 21(9):978-e78.

26. Arnold M, Mura A, Langhans W, Geary N (2006) Gut vagal afferents are not necessary for the eating-stimulatory effect of intraperitoneally injected ghrelin in the rat. J Neurosci. 26(43):11052-11060.

27. Koizumi M, Dezaki K, Hosoda H, Damdindorj B, Sone H, Ming L, Hosoya Y, Sata N, Kobayashi E, Kangawa K, Nagai H, Yasuda Y, Yada T (2010) Reconstructiondependent recovery from anorexia and time-related recovery of regulatory ghrelin system in gastrectomized rats. Int J Pept. pii: 365416.

28. Burggraf KK, Willing AE, Koopmans HS (1997) The effects of glucose or lipid infused intravenously or intragastrically on voluntary food intake in the rat. Physiol Behav 61(6):787-793.

29. Koopmans HS (1995) The effect of infused nutrients and absorbed foods on daily food intake in rats. Obes Res 3 Suppl 5:675S-684S.

30. Masuda Y, Tanaka T, Inomata N, Ohnuma N, Tanaka S, Itoh Z, Hosoda H, Kojima M, Kangawa K (2000) Ghrelin stimulates gastric acid secretion and motility in rats. Biochem Biophys Res Commun 276(3):905-908.

31. Nakazato M, Murakami N, Date Y, Kojima M, Matsuo H, Kanagawa K, Matsukura S (2001) A role for ghrelin in the central regulation of feeding. Nature 409: 194198.

32. Shintani M, Ogawa Y. Ebihara K, Aizawa-Abe M, Miyanaga F, Takaya K, Hayashi T, Inoue G, Hosoda K, Kojima M, Kanagawa K, Nakao K (2001) Ghrelin, an endogenous GH secretagogue, is a novel orexigenic peptide that antagonizes leptin action through the activation of hypothalamic neuropeptide Y/Y1 receptor pathway. Diabetes 50: 227-323. 